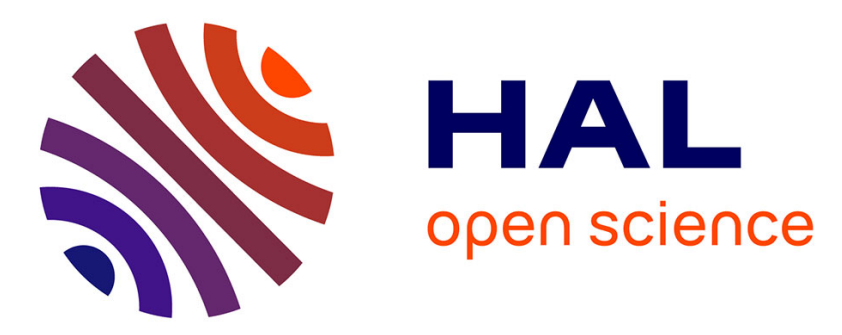

\title{
Acute 19-nortestosterone transiently suppresses hippocampal MAPK pathway and the phosphorylation of the NMDA receptor
}

Uwe L. Rossbach, Madeleine Le Grevès, Fred Nyberg, Qin Zhou, Pierre Le Grevès

\section{To cite this version:}

Uwe L. Rossbach, Madeleine Le Grevès, Fred Nyberg, Qin Zhou, Pierre Le Grevès. Acute 19-nortestosterone transiently suppresses hippocampal MAPK pathway and the phosphorylation of the NMDA receptor. Molecular and Cellular Endocrinology, 2009, 314 (1), pp.143. 10.1016/j.mce.2009.07.027 . hal-00529005

\section{HAL Id: hal-00529005 https://hal.science/hal-00529005}

Submitted on 24 Oct 2010

HAL is a multi-disciplinary open access archive for the deposit and dissemination of scientific research documents, whether they are published or not. The documents may come from teaching and research institutions in France or abroad, or from public or private research centers.
L'archive ouverte pluridisciplinaire HAL, est destinée au dépôt et à la diffusion de documents scientifiques de niveau recherche, publiés ou non, émanant des établissements d'enseignement et de recherche français ou étrangers, des laboratoires publics ou privés. 


\section{Accepted Manuscript}

Title: Acute 19-nortestosterone transiently suppresses hippocampal MAPK pathway and the phosphorylation of the NMDA receptor

Authors: Uwe L. Rossbach, Madeleine Le Grevès, Fred Nyberg, Qin Zhou, Pierre Le Grevès

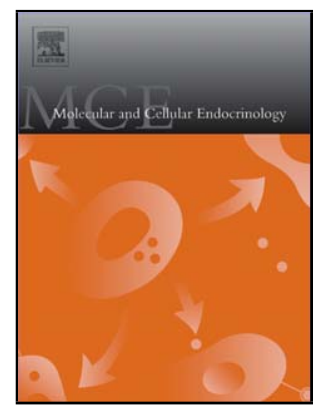

PII:

DOI:

Reference:

S0303-7207(09)00398-0

To appear in: $\quad$ Molecular and Cellular Endocrinology

Received date: $\quad$ 12-5-2009

Revised date: $\quad 3-7-2009$

Accepted date: $\quad$ 26-7-2009

Please cite this article as: Rossbach, U.L., Le Grevès, M., Nyberg, F., Zhou, Q., Le Grevès, P., Acute 19-nortestosterone transiently suppresses hippocampal MAPK pathway and the phosphorylation of the NMDA receptor, Molecular and Cellular Endocrinology (2008), doi:10.1016/j.mce.2009.07.027

This is a PDF file of an unedited manuscript that has been accepted for publication. As a service to our customers we are providing this early version of the manuscript. The manuscript will undergo copyediting, typesetting, and review of the resulting proof before it is published in its final form. Please note that during the production process errors may be discovered which could affect the content, and all legal disclaimers that apply to the journal pertain. 
Acute 19-nortestosterone transiently suppresses hippocampal MAPK pathway and the phosphorylation of the NMDA receptor

Uwe L. Rossbach ${ }^{\mathrm{a}}$, Madeleine Le Grevès ${ }^{\mathrm{b}}$, Fred Nyberg ${ }^{\mathrm{a}}$, Qin Zhou ${ }^{\mathrm{a}}$ and Pierre Le Grevès $^{\mathrm{c}^{*}}$

${ }^{a}$ Department of Pharmaceutical Biosciences, Division of Biological Research on Drug Dependence, Uppsala University, BMC, Box 591, S-751 24 Uppsala, Sweden ${ }^{b}$ Department of Neuroscience, Unit of Functional Pharmacology, Uppsala University, BMC, Box 593, S-751 24 Uppsala, Sweden

${ }^{\mathrm{c}}$ Department of Neuroscience, Division of Neurobiology, Uppsala University, BMC, Box 587, S-751 23 Uppsala, Sweden

* Correspondence to: Pierre Le Grevès, Department of Neuroscience

Division of Neurobiology, Uppsala University,

BMC, Box 587, S-751 23 Uppsala, Sweden

E-mail: pierre.legreves@neuro.uu.se,

Telephone: +4618471 44384, Fax: +46 18559017

Keywords: Anabolic androgenic steroids; phosphorylation; ERK; NMDA receptor; hippocampus; synaptoneurosomes 


\begin{abstract}
High doses of anabolic androgenic steroid are associated with changes in personality, e.g. increased aggression and irritability, behavioural changes that may be linked to structural changes in the hippocampus. In this in vivo study we demonstrate acute effects of a single injection of 19-nortestosterone on proteins that play a major role in molecular plasticity at synaptic connections. The steroid rapidly and transiently decreased total and phosphorylated NMDA receptor GluN2B subunit levels and phosphorylated extracellular signal-regulated kinase 1 in rat hippocampal synaptoneurosomes. Pretreatment with the androgen receptor antagonist flutamide prevented these effects suggesting an androgen receptor mediated mode of action. However, flutamide alone stimulated the phosphorylation of both extracellular signal-regulated kinase 1 and 2. EphrinB2 and phosphorylated translation initiation factor $4 \mathrm{E}$, two proteins that act on synaptic plasticity through NMDA receptor and/or mitogen-activated protein kinase pathways, were not affected by any of the treatment regimens. This study demonstrates rapid in vivo effects of an anabolic androgenic steroid on two key elements in hippocampal synaptic plasticity.
\end{abstract}




\section{Introduction}

Research during the past two decades has presented evidence that gonadal steroids can modulate neuronal activity in the hippocampus (for review see [1]), a brain structure that plays a vital role in cognition and mood. Estrogens have a well-documented impact on hippocampal neurophysiology and recently it has become clear that androgens exert similar effects although the underlying mechanisms remain relatively unexplored. Androgenic receptors (AR) are present in the hippocampus [2] and several studies have demonstrated that androgens can enhance and restore cognitive performance (for review see [3]).

Classical steroid action regulating gene expression is mediated through nuclear receptors and the effects typically occur in days, however, today it is known that steroid-induced changes in neuronal cell signalling and behaviour can take place within minutes or hours [4]. Such rapid action are suggested to engage extranuclear mechanisms e.g. modulation of GABA [5] and NMDA receptors (NMDAR) [6]or sex steroid receptors located in the cell membrane $[7,8]$, often involving posttranslational modifications of synaptic components, e.g. phosphorylation of NMDARs and extracellular signal-regulated kinase (ERK). For example androgens have been shown in vitro to regulate the phosphorylation of ERK within minutes $[9,10]$.

A growing amount of evidence from studies in humans shows that abuse of high doses of anabolic androgenic steroids (AAS) induce changes in mood and personality [11] that are often expressed as increased irritability and bad temper[12]. Increased aggression has also been demonstrated in rats[13]. In addition, androgens are associated to decreased anxiety in rodents[14,15], an effect that may occur within minutes [16]. The underlying molecular mechanism for these effects is still not well known, however, phosphorylation of hippocampal NMDAR and ERK has been linked to fear and anxiety. For example, a reduction in their phosphorylation state are shown to impair the retrieval of contextual fear memory in mice $[17,18]$.

In an earlier report we studied the effects of a single or repeated high doses (daily for 14 days) of an AAS on selected elements in hippocampal synaptoneurosomes. This preparation is often used in studies of the regulation of proteins and downstream signalling pathways in close proximity to the synapse. The (sub)chronic administration of AAS did not alter any of the protein or phosphoprotein studied. However, twenty-four hours after the single dose, AAS induced an increase in the phosphorylation of the NMDAR subunits GluN2A and GluN2B and ERK1/2[19]. Such modifications are considered to constitute important regulatory steps in the cascade underlying synaptic plasticity. To investigate the rapidity of these responses to AAS we here describe the acute effect of 19-nortestosterone (19NT) in hippocampal synaptoneurosomes two and six hours after a single systemic injection of the steroid. The AR antagonist flutamide was included in order to clarify whether classical ARs were involved. In search for proteins engaged in the phosphorylation of the NMDAR and ERK, we also studied the eukaryotic initiation factor 4E (eIF4E). This factor, known to be activated by ERK, is essential for mRNA translation and as such considered to be a marker and regulator of 
synaptodendritic protein synthesis underlying structural plasticity [20]. Furthermore, we determined the protein levels of ephrinB2, an ERK regulated synaptic component that can stimulate the phosphorylation of GluN2B at Y1472 though the src family kinase Fyn $[21,22]$. The results show that $19 \mathrm{NT}$ acutely and transiently decreases phosphorylated GluN2B and ERK through a flutamide sensitive pathway.

\section{Materials and methods}

The study was approved by the local experimental animal committee. Male SpragueDawley rats (Alab, Sollentuna, Sweden), weighing 250 to $275 \mathrm{~g}$, were housed in airventilated rooms (humidity 50-60\%, temperature $22-24^{\circ} \mathrm{C}$ ) under a $12 \mathrm{~h}$-dark $/ 12 \mathrm{~h}$-light cycle with food and water provided ad libitum. The animals were randomly divided into five groups (assigned oil+oil, oil+19NT, oil+19NT 6 h, Flu+oil, Flu+19NT), each consisting of six rats. Three groups of animals, oil +oil, oil $+19 \mathrm{NT}$ and oil $+19 \mathrm{NT} 6 \mathrm{~h}$, were daily treated with $250 \mu 1$ peanut oil (Apoteket $\mathrm{AB}$, Sweden) injection during 5 days. The other two groups Flu+oil and Flu+19NT received daily flutamide (Sigma, F9397) administration during 5 days $(15 \mathrm{mg} / \mathrm{kg} /$ day in $250 \mu \mathrm{l}$ peanut oil). Five hours after the last injection, the animals in the groups of oil $+19 \mathrm{NT}$, oil $+19 \mathrm{NT} 6 \mathrm{~h}$ and Flu $+19 \mathrm{NT}$ received a single dose of 19NT (Sigma, N7252) (3 mg/kg dissolved in 10\% ethanol in peanut oil). Rats in the groups of oil+oil and Flu+oil were injected with $50 \mu 110 \%$ ethanol in peanut oil. The animals were decapitated $2 \mathrm{~h}$ after the last injection except for the rats of the oil +19 NT $6 \mathrm{~h}$ group. Animals of the oil $+19 \mathrm{NT} 6 \mathrm{~h}$ group were killed $6 \mathrm{~h}$ after the administration of the steroid. Right and left hippocampus was rapidly dissected out on ice, using a rat brain matrix (Activational System Inc., Mortella Drive Warren, MI, USA), and placed on dry ice. The tissues were kept at $-80^{\circ} \mathrm{C}$ until further processing

\subsection{Synaptoneurosome preparation}

A preparation of rat synaptoneurosomes, enriched for synaptic components, was isolated according to the method of Hollingsworth et al [23]. Using a Teflon pestle homogeniser, individual left hippocampi were homogenised in 10 volumes of ice-cold buffer $\mathrm{pH} 7.4$ (HEPES $50 \mathrm{mM}, \mathrm{NaCl} 124 \mathrm{mM}, \mathrm{NaHCO}_{3} 26 \mathrm{mM}$, glucose $10 \mathrm{mM}, \mathrm{MgCl}_{2} 1.3 \mathrm{mM}$, $\mathrm{CaCl}_{2} 2.5 \mathrm{mM}, \mathrm{KCl} 3.2 \mathrm{mM}, \mathrm{KH}_{2} \mathrm{PO}_{4} 1.06 \mathrm{mM}$, chloramphenicol $0.7 \mathrm{mM}$, saturated with $95 \% \mathrm{O}_{2} / 5 \% \mathrm{CO}_{2}$ ) containing phosphatase inhibitor cocktail $1 \& 2$ (Sigma, P2850 \& P5726) and protease inhibitors (Complete Mini tablets, Roche). The crude homogenate was diluted, mixed with an additional 10 volumes of the ice-cold homogenisation buffer and incubated on ice for $10 \mathrm{~min}$. The preparation was filtered through two layers of 80 $\mu \mathrm{m}$ nylon net filter disks (NY8002500, Millipore) and the filtrates were then passed through a $5 \mu \mathrm{m}$ Durapore ${ }^{\circledR}$ membrane (SVLP01300, Millipore). The filtered solutions were centrifuged at $1000 \mathrm{x} \mathrm{g}$ for $15 \mathrm{~min}$ at $4^{\circ} \mathrm{C}$, the pellets were resuspended in 8 volumes of homogenisation buffer and aliquots were kept at $-80^{\circ} \mathrm{C}$. Protein concentration was determined by use of a commercial kit (BCA Kit, Pierce). The GluN2A and GluN2B subunit proteins were used as markers for the accumulation of synaptic proteins in the synaptoneurosome preparation. Moreover, the content of ERK1/2, eIF4E and ephrinB2 was determined in the different fractions. 


\subsection{Western blotting}

A randomized block design was used for the analysis. Ten or twenty $\mu \mathrm{g}$ of protein (depending on protein analysed) were resolved on 10\% SDS-polyacrylamide gels and transferred to a $0.45 \mu \mathrm{m}$ nitrocellulose membrane (Hybond ${ }^{\mathbb{B}}$-ECL, GE Healthcare). Blots were incubated with specific antibodies recognising the following proteins: ERK1/2 (\#9102, 1:1500, New England Biolabs) and p-ERK1/2 (1:3000, \#9101, New England Biolabs); p-GluN2 ${ }^{\text {S1232 }}$ (1:10000, \#2056, Tocris Bioscience); p-GluN2B ${ }^{\mathrm{Y} 1472}$ (1:3000, SIG-9063, Signet Laboratories); GluN2A (1:40 000, sc-1468, Santa Cruz), GluN2B (1:20000, sc-1469, Santa Cruz); p-eIF4E (1:2500, \#9741, Cell Signalling); eIF4E (1:10000, \#9742, Cell Signalling); ephrinB2 (1:24000, a generous gift from Dr. Klas Kullander, Dept. of Neuroscience, Uppsala University). The preparations were subsequently incubated with the corresponding secondary horseradish peroxidase (HRP) conjugated antibodies (Santa Cruz). Immunoblots were visualised using standard chemiluminescence reagent or enhanced chemiluminescence reagent (ECL Detection Reagent, GE Healthcare) when appropriate and exposed to Cronex 5 light-sensitive film (Agfa Gevert). When stripped, the filters were washed with a buffer containing $100 \mathrm{mM}$ 2-mercaptoethanol, $2 \% \mathrm{SDS}$ and $62.5 \mathrm{mM}$ Tris- $\mathrm{HCl}, \mathrm{pH} 6.8$, at $55^{\circ} \mathrm{C}$ for 20 minutes. The Image J $1.37 \mathrm{p}$ software (NIH, USA) was used to quantify the band density of the scanned films. Protein quantification, inter-lane uniformity in loading and transfer was verified in two separate western blots where $10 \mu \mathrm{g}$ protein from each individual biological sample were loaded on $10 \%$ SDS-polyacrylamide gels and subsequently transferred to nitrocellulose membranes. The total protein content of each sample transferred to the membrane was quantified by use of MemCode ${ }^{\circledR}$ protein staining (Thermo Fisher Scientific, Rockford, USA).

\subsection{Biochemical characterization of the synaptoneurosomal preparation}

The distribution of the proteins studied was determined in crude homogenate, synaptoneurosomes and supernatant prepared as described in section 2.2. Equal amounts of protein from respective fraction were analysed by western blot as described above (section 2.3).

\subsection{Real time quantitative PCR}

For real time quantitative polymerase chain reaction (qPCR), total RNA was isolated from right hippocampus (TRIzol ${ }^{\circledR}$ reagent, Invitrogen) and treated with DNase (Promega M610A). RNA quality was controlled with respect to 28S/18S ratio (Experion Automated Electrophoresis System, RNA StdSens Analysis Kit, Bio-Rad Laboratories) and the absence of genomic DNA was confirmed by PCR. cDNA was synthesised (Superscript III Kit, Invitrogen) according to the manufacturer's protocol. qPCR was performed in an iCycler iQ multicolor real time detection system (Bio-Rad Laboratories) in a reaction mixture consisting of cDNA (corresponding to $25 \mathrm{ng}$ transcribed RNA), $20 \mu 1$ of $20 \mathrm{mM}$ Tris-HCL pH 8.4, $50 \mathrm{mM} \mathrm{KCl,} 4 \mathrm{mM} \mathrm{MgCl} 2,0.2 \mathrm{mM}$ dNTP, SYBR Green 1:50000, 12.5 $\mathrm{nM}$ fluorescein, $0.25 \mu \mathrm{M}$ of forward and reverse primer and $0.04 \mathrm{U} / \mu \mathrm{l}$ Taq DNA polymerase. The following conditions were applied for the qPCR reaction; $95^{\circ} \mathrm{C}$ for 3 min followed by 50 cycles at $95^{\circ} \mathrm{C}$ for $15 \mathrm{sec}, \mathrm{T}_{\mathrm{a}}$ for $15 \mathrm{sec}$ and $72^{\circ} \mathrm{C}$ for $30 \mathrm{sec}$. A melting point curve was recorded for each run to confirm that only one single product was formed. All qPCR experiments were performed in triplicates on individual samples 
and negative controls. The analysis of the qPCR experiments was conducted as follows. The cycle threshold (ct) values were obtained from the iCycler 3.0.6 software (Bio-Rad Laboratories) and the triplicate averages were transformed into quantities between 0 and 1 , where the highest relative quantity (lowest ct value) was set to 1 . To test for the most stable set of house-keeping genes (HKG) as reference we used the method of Vandesompele et al. [24]. Out of 7 genes histone $H 3, \beta$-actin and $\beta$-tubulin were selected using the GeNorm software [24]. The obtained normalisation factors were used for normalisation of GluN2A and GluN2B mRNA levels.

The following primer sequences with the corresponding annealing temperatures $\left(T_{a}\right)$ were used: histone $\mathrm{H} 3,\left(\mathrm{~T}_{\mathrm{a}}: 60.0^{\circ} \mathrm{C}\right)$ : forward 5'-ATT CGC AAG CTC CCC TTT CAG-3', reverse 5'-TGG AAG CGC AGG TCT GTT TTG-3'; $\beta$-actin, $\left(\mathrm{T}_{\mathrm{a}}: 60.0^{\circ} \mathrm{C}\right)$ : forward 5'CAC TGC CGC ATC CTC TTC CT-3', reverse 5'-AAC CGC TCA TTG CCG ATA GTG-3'; $\beta$-tubulin $\left(\mathrm{T}_{\mathrm{a}}: 60.0^{\circ} \mathrm{C}\right)$ : forward 5'-CGG AAG GAG GCG GAG AGC-3', reverse 5'-AGG GTG CCC ATG CCA GAG C-3'; GluN2A, $\left(\mathrm{T}_{\mathrm{a}}: 61.0^{\circ} \mathrm{C}\right)$ : forward 5'CAG CAG CAG GCC ACA GTT ATG-3', reverse 5'-AGT CTC GGT AGC CAG GGG AG-3'; GluN2B, $\left(\mathrm{T}_{\mathrm{a}}: 62.8^{\circ} \mathrm{C}\right)$ : forward 5'-GTG AAC AAG ATC CGC AGT ACC ATC3', reverse 5'-CTT AGA GTC GCC ATC GTC CAG AG-3'.

\subsection{Immunoprecipitation and detection of the androgen receptor}

Immunoprecipitation was performed using a commercially available kit (Dynabeads ${ }^{\circledR}$ Protein A, Invitrogen). As an AR positive control for we used LNCaP cells. The synaptoneurosomes or LNCaP cells were treated with lysis buffer $(10 \mathrm{mM}$ Tris- $\mathrm{HCl} \mathrm{pH}$ 7.4, $100 \mathrm{mM} \mathrm{NaCl}, 1 \mathrm{mM}$ EDTA, $1 \mathrm{mM}$ EGTA, $1 \mathrm{mM} \mathrm{NaF}, 20 \mathrm{mM} \mathrm{Na}_{4} \mathrm{P}_{2} \mathrm{O}_{7}, 2 \mathrm{mM}$ $\mathrm{Na}_{3} \mathrm{VO}_{4}, 1 \%$ Triton $\mathrm{X}-100,10 \%$ glycerol, $0.1 \%$ SDS, $0.5 \%$ deoxycholate, supplemented with phosphatase inhibitor cocktail $1 \& 2$ (Sigma, P2850 \& P5726) and protease inhibitors (Complete Mini tablets, Roche) at a ratio of 1:2) for 30 min at $4{ }^{\circ} \mathrm{C}$. After a subsequent centrifugation at $18000 \mathrm{x}$ g for $10 \mathrm{~min}$ the clear lysate was collected. For immunoprecipitation AR antibody ( $5 \mu \mathrm{g}$, sc-815, SantaCruz) was bound to the beads and subsequently incubated with lysates for $15 \mathrm{~min}$ at room temperature. After three washes the antigen was eluted and denatured by heat. The eluates were loaded onto an 8\% SDSpolyacrylamide gel and the AR protein was identified by western blot as described in section 2.3. Blots were incubated with a specific AR antibody (PG-21) (1:50000; Millipore, \#06-680) followed by incubation with anti-rabbit secondary HRP conjugated antibody (Bio-Rad, \#172-1019). The immunoblots were visualised as described in section 2.3 .

\subsection{Data analysis and statistics}

For the determination of phosphorylated proteins the ratio of phosphorylated to total protein was calculated for each individual animal. The mean values from the treated groups were expressed as a percentage of the mean value from the control group. Data are expressed as means \pm SEM. Differences between the groups of animals were calculated using one-way ANOVA. When the ANOVA reached a significant level $(P<$ $0.05)$ a Fischer's PLSD post-hoc test was computed. Statistical analysis was performed in StatView software (StatView 5.0.1, SAS Institute, 1998). $P<0.05$ was considered as significant level. 


\section{Results}

\subsection{Protein profile of the hippocampal synaptoneurosome preparation}

The different fractions of the hippocampal synaptoneurosome preparation (crude homogenate, synaptoneurosomes and supernatant) were analysed for their content of GluN2A, GluN2B, ERK1/2, eIF4E and ephrinB2 (Fig. 1). The NMDAR subunits showed as expected an accumulation in the synaptoneurosomal fraction. The levels of ERKs and eIF4E were reduced in synaptoneurosomes while the ephrinB2 concentrations did not vary notably between the three fractions.

\subsection{Validation of the western blot analysis}

The determination of all proteins was performed by western blot analysis. MemCode ${ }^{\circledR}$ protein staining was used for the validation of protein quantification and inter-lane uniformity in protein loading and transfer, yielding a coefficient of variance $(\mathrm{CV})$ of 7.2 $\%$.

\subsection{The effect of 19NT on ERKs and the impact of flutamide}

The phosphorylation of ERK1 (Fig. 2A) and ERK2 (Fig. 2B) were significantly altered by the treatment with flutamide and/or $19 \mathrm{NT}\left(F_{3,18}=12.8, P<0.001 ; F_{3,18}=6.41, P<\right.$ 0.01 , respectively, one-way ANOVA). The post-hoc test (Fisher's PLSD) revealed a significant decrease of the ERK1 phosphorylation and a tendency to a decrease of phosphorylated ERK2 levels two hours after the administration of 19NT (p-ERK1; $66.1 \pm$ $6.8 \%, P<0.01, \mathrm{p}$-ERK2; $84.2 \pm 4.7 \%, P=0.07)$. When the rats were treated with flutamide prior to the administration of 19NT, p-ERK1 levels were not only restored but were significantly higher compared to the control group $(129 \pm 7.5 \%, P<0.001$ compared to oil $+19 \mathrm{NT} ; P<0.05$ compared to oil + oil $)$. Regarding $\mathrm{p}$-ERK2, the latter treatment regimen resulted in significantly higher levels compared to animals treated with oil +19 NT $(118 \pm 6.7 \%, P<0.01)$. Surprisingly, the five-days pretreatment with flutamide alone resulted in stimulation of both ERK1 and ERK2 phosphorylation $(123.8 \pm 10.5 \%, P$ $<0.05 ; 129.1 \pm 7.4 \%, P<0.05$, respectively).

\subsection{The effect of 19NT on NMDA receptor subunits and the impact of flutamide} The one-way ANOVA analysis of the effects of the flutamide and/or 19NT treatment on

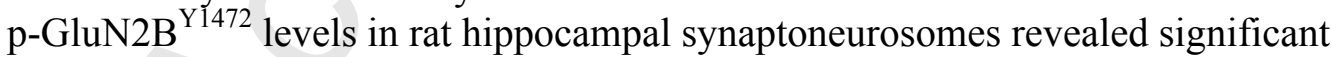
differences between the groups of rats $\left(F_{3,18}=4.74, P<0.05\right)$. Post hoc test (Fisher's PLSD) showed that $\mathrm{p}$-GluN2B ${ }^{\mathrm{Y} 1472}$ was significantly decreased $(63 \pm 10 \%, P<0.05)$ two hours after the administration of 19NT when compared to control animals $(100 \pm 10 \%)$ (Fig. 2C). While pretreatment with the androgen receptor antagonist flutamide alone had no statistically significant effect on p-GluN2B ${ }^{\mathrm{Y} 1472}$, it completely blocked the effect induced by $19 \mathrm{NT}$ at $2 \mathrm{~h}(118.6 \pm 18.0 \%, P<0.01)$ (Fig. $2 \mathrm{C})$. Significant differences between the groups of animals were also found for total GluN2B protein $\left(F_{3,17}=3.86, P\right.$ $<0.05$, one-way ANOVA) (Fig. 2D). The levels of GluN2B tended to be reduced two hours after the injection of 19NT, an effect that almost reached a significant level $(87.2 \pm$ $4.9 \%, P=0.06$, Fisher's PLSD). Flutamide pretreatment resulted in significantly higher 
levels of GluN2B compared to this latter group of rats $(108.1 \pm 2.5 \%, P<0.01$, Fisher's PLSD). The levels of p-GluN2 $\mathrm{A}^{\mathrm{S} 1232}$ and GluN2A were not affected in any of the animal groups (Fig. 4A-B).

\subsection{Time-dependent alterations of GluN2B and ERK phosphorylation after 19NT administration}

To investigate if the time of exposure influenced the effect of 19NT on NMDAR and ERK phosphorylation, we included a group of animals that were sacrificed six hours after the injection of 19NT. The results (Fig 3A-D) showed a significant impact of time on pGluN2B ${ }^{\mathrm{Y} 1472}$ and p-ERK1 levels $\left(F_{2,14}=7.64, P<0.01 ; F_{2,14}=6.32, P<0.05\right.$, respectively, one-way ANOVA). The decrease in phosphorylation of GluN2B ${ }^{\text {Y1 }}{ }^{\text {, }}$, ERK1 and ERK2 detected two hours after androgen administration was restored after six hours $(111 \pm 5.5 \%, P<0.01 ; 121 \pm 16 \%, P<0.05 ; 112 \pm 9.8 \%, P<0.05$, respectively, Fisher's PLSD post-hoc test). Although phosphorylated protein levels six hours after 19NT administration tended to be higher compared to control levels, they never reached significant levels. GluN2B levels were also transiently decreased (one-way ANOVA $\left(F_{2}\right.$, $\left.{ }_{13}=5.57, P<0.05\right)$ with a significant reduction two hours after $19 \mathrm{NT}$ administration $(87.2 \pm 4.9 \%, P<0.05)$ and restored levels at six hours $(102.6 \pm 3.3 \%, P<0.01)$

\subsection{The effect of 19NT and flutamide on p-eIF4E and ephrinB2}

Western blot analysis of the hippocampal synaptoneurosomal fraction revealed that the treatment regimens neither affected the phosphorylated form of the marker for synaptodendritic protein synthesis eIF4E nor the protein amount of the Eph receptor ligand ephrinB2 (Fig. 4).

\subsection{Determination GluN2A, GluN2B and ephrinB2 mRNA levels}

Quantitative real time PCR was performed to investigate if the 19NT-induced decrease in GluN2B protein levels at two hours reflected downregulated mRNA expression levels. Also the transcript for GluN2A was determined. However, neither GluN2B nor GluN2A mRNA expression was affected by $19 \mathrm{NT}$ or sub-chronic flutamide administration (Tab.1).

\subsection{Detection of $A R$ in the synaptoneurosomal preparation and $L N C a P$ cells}

To investigate the presence of AR in our hippocampal synaptoneurosome fraction, western blot analysis was performed on immunoprecipitate from synaptoneurosomes or whole cell extract from the AR containing human prostate $\mathrm{LNCaP}$ cell line. Figure 5 displays a single immunoreactive entity in synaptoneurosomes. The molecular mass (approx. $110 \mathrm{kD}$ ) was found to be similar to that of the AR detected in LNCaP cells.

\section{Discussion}

In this study we determined the acute effect of a single systemic dose of the AAS 19NT on selected key elements in hippocampal synaptoneurosomes. This synaptic subcellular fraction is suitable for studies of the regulation of proteins at synapses. As expected, 
NMDAR subunits are accumulated in this preparation while ERKs and eIF4E are reduced (Fig. 1). Nevertheless, both ERKs and eIF4E play important roles in protein synthesis locally at synapses $[25,26]$. EphrinB2 at its synaptic localisation, is believed to be involved in synaptic plasticity [27], however in our fractions it is evenly distributed supporting the findings that it is also present in neuronal cell bodies in rodent hippocampus [28].

Two hours after $19 \mathrm{NT}$ administration the phosphorylation state of the NMDA receptor subunit GluN2B was decreased while that of the GluN2A subunit was unaffected. Simultaneously, p-ERK1 (and p-ERK2 to some extent) declined in a comparable manner. These declines were blocked when the AR antagonist flutamide was administrated daily during five days prior to the acute dose of 19NT. This suggests an AR mediated mode of action. Six hours after the injection of $19 N T$, the levels of $p-G l u N 2 B^{\text {Y1472 }}$ and p-ERK1 were restored. Moreover, the antiandrogen flutamide exerted its own effects by significantly increasing p-ERK1 and p-ERK2 levels.

The published effects of androgens and antiandrogens on cell signalling are in part inconsistent and the underlying mechanisms remain unclear. For example, flutamide or its active metabolite hydroxyflutamide mimic rather than inhibit androgen-induced phosphorylation of ERK in prostate [29,30] and breast cancer cell lines [31]. It is speculated that this effect is mediated through a non-genomic pathway involving extranuclear ARs which, in fact have been visualised in rat hippocampal axons and dendrites by immunocytochemistry [32]. Since these morphological components are enriched in the synaptoneurosomes, they may represent the origin for the immunoprecipated ARs that we detect in this preparation. In both intact and AR deficient mice, DHEA and flutamide increase hippocampal dendritic spine synapse number [33], a process that is known to depend on NMDAR regulated MAPK signalling [34]. Conversely, a differential effect of androgens and flutamide on ERK activation has also been observed. In glial C6 cells, dihydrotestosterone (DHT) increased ERK phosphorylation in a flutamide sensitive manner while membrane-impermeable DHTBSA decreased p-ERK, an effect that flutamide was unable to block [9]. The authors of that study suggested that nuclear AR mediated the stimulatory effect while a distinct membrane AR was responsible for the decline in p-ERK.

Our study was performed on intact male rats, which comprise an in vivo system much different from isolated cells. Interpreting the effect of 19NT alone, and 19NT in combination with flutamide pretreatment, it appears that the steroid acts through flutamide sensitive ARs. However, the increase in p-ERK seen after the administration of flutamide is difficult to explain. Subchronic AR antagonist treatment is considered to block nuclear ARs and to decrease AR gene expression in the hippocampus [2]. Since the rats used in our study were gonadally intact, a normal testosterone production could be assumed. If androgens exert a constitutive suppression of ERK phosphorylation, a block of the basal endogenous androgen tonus by AR antagonists may result in elevated p-ERK levels in the respective group of animals. Regarding 19NT, the effects appear after two hours, which is a relatively short period of time for the steroid to act via its nuclear receptor in a classical genomic way. The decreased phosphorylation induced by $19 \mathrm{NT}$ is 
in line with the previously published effect of membrane-impermeable DHT-BSA in C6 cells [9] and may thus reflect an involvement of a membrane-associated AR receptor. However, if the two effects mediated by the different targets are opposing why was 19NT not able to reduce the flutamide-induced increase in p-ERK1? Possible explanations may be that the steroid concentration was too low or that the effects induced by $19 \mathrm{NT}$ alone are also mediated through classical ARs.

The 19NT-induced decrease in $\mathrm{p}-\mathrm{GluN} 2 \mathrm{~B}^{\mathrm{Y} 1472}$ discussed above was paralleled by a decline in the levels of GluN2B. This is consistence with the notion that Fyn kinase mediated phosphorylation of GluN2B ${ }^{\mathrm{Y} 1472}$ regulates the localisation of GluN2B containing NMDARs to the synaptic membrane $[35,36]$. To rule out that the altered GluN2B level was due to decreased GluN2B transcription, we determined its mRNA expression by qPCR. The observation that GluN2B mRNA levels were unchanged argues against transcriptional regulation in our study. Likewise, translation does not seem to be affected either, since there was no change in the levels of the activated (phosphorylated) form of the translation initiation factor eIF4E that regulates the translation of most mRNAs [37]. Thus, it appears that the depleted GluN2B protein levels observed in the present study are a consequence of increased internalisation due to decreased phosphorylation of GluN2B ${ }^{\mathrm{Y} 1472}$. Nateri et al. [21] suggests that MEK1 overexpression in mice leads to elevated hippocampal GluN2B protein levels through increased ERK phosphorylation and subsequent activation of eIF4E. In that study, GluN2B levels were not associated with those of phosphorylated GluN2B ${ }^{\mathrm{Y} 1472}$. We observe analogous changes in the levels of p-ERK, p-GluN2B ${ }^{\mathrm{Y} 1472}$ and GluN2B although p-eIF4E remained unchanged. These findings indicate a connection between NMDAR regulation and ERK activation in the rodent hippocampus. It is known that phosphorylation of GluN2B ${ }^{\text {Y1472 }}$ affects NMDAR activity [38], which in turn has been shown to regulate the phosphorylation of ERK in the synaptosomal compartment [39]. This mechanism is believed to represent a link in dendritic local protein synthesis essential for synaptogenesis. Although androgens are reported to stimulate synaptogenesis [40], our results do not support an engagement of eIF4E in the synaptic fraction at least not within the time frame tested in the present investigation. Looking up-stream of NMDAR regulation, ephrinB2 is a protein that stimulates the phosphorylation of GluN2B at Y1472 through Fyn kinase [21,22]. Moreover, it is also known to regulate synaptic plasticity [27]. We were however not able to detect any changes in ephrinB2 protein levels suggesting that the regulation of GluN2 $\mathrm{B}^{\mathrm{Y} 1472}$ in this study, depends on alternative pathways.

Interestingly, phosphorylation of the GluN2B subunit at Y1472 and ERK in the hippocampus has been linked to fear and anxiety. A reduction of the phosphorylation state in the hippocampus is shown to impair the retrieval of contextual fear memory in mice $[17,18]$. Androgens are reported to affect mood and while long-term treatment with AAS is anxiogenic in rats [41,42], testosterone has been shown to rapidly (after $30 \mathrm{~min}$ ) decrease anxiety in mice [16]. Moreover, male rats with recent sexual experience show increased hippocampal testosterone and decreased anxiety-like behaviour [43]. In humans, a single dose of testosterone reduces fear-potentiated startle when tested four hours after the administration [44]. In view of our results showing that AAS acutely (after 
two hours) decrease hippocampal p-GluN2B ${ }^{\mathrm{Y} 1472}$ and p-ERK1, it is interesting to note reports on criminals that prime themselves with AAS to become more calm prior to a criminal act [45]. This may thus represent a direct application on a fast steroid-induced effect on NMDAR and ERK phosphorylation. Furthermore, flutamide has been demonstrated to increase anxiety-like behaviour in rats [46] and in humans [47], an effect that is in accordance with increased p-ERK levels as seen in the group of rats treated with flutamide alone.

An alternative non-genomic pathway for the action of 19NT could be a direct or indirect interaction with ion channels. The function of ion channels such as NMDA and GABA receptors can be rapidly modulated by neurosteroids through allosteric interactions at receptor sites [48]. AAS and neurosteroids show structural similarity, yet they can distinctively modulate the $\mathrm{GABA}_{\mathrm{A}}$ receptor due to differences at critical moieties [49]. With respect to the NMDAR we have previously shown that the neurosteroids, e.g. pregnenolone sulfate and pregnanolone sulfate, differentially interacts with the GluN2B subunit via an allosteric modulation [6,50]. We know that chronic administration (21 days) of 19NT to rats does not affect that modulation of the receptor subunit (unpublished data). However, studies addressing an acute impact of AAS in that context have not been conducted. In view of the study by Chen et al.[51], demonstrating that pregnenolone sulfate rapidly stimulates the phosphorylation of ERK and GluN2B when applied to hippocampal slices, and the fact that structurally different neurosteroids often display differential effects, one could speculate on a mechanism where 19NT, or metabolites thereof, act oppositely to pregnenolone sulfate.

In summary, a single injection of the androgenic steroid 19NT acutely and transiently decreased the phosphorylation of the GluN2B subunit of the NMDA receptor and ERK1 in rat hippocampal synaptoneurosomes. Pretreatment with flutamide abolished the effect indicating an AR mediated mode of action, however, flutamide displayed an effect of its own increasing both p-ERK1 and p-ERK2. The results show that androgens have a fast in vivo effect on major players in structural synaptic plasticity although the markers for synaptogenesis tested here were not affected by the treatment. Whether acute AAS decreases anxiety-like behaviour in the rat, as indicated by the effect on $\mathrm{p}-\mathrm{GluN} 2 \mathrm{~B}^{\mathrm{Y} 1472}$ and $\mathrm{p}$-ERK1, is an issue for further investigation. 
References:

[1] Parducz, A., Hajszan, T., Maclusky, N.J., Hoyk, Z., Csakvari, E., Kurunczi, A., Prange-Kiel, J. and Leranth, C. (2006) Synaptic remodeling induced by gonadal hormones: neuronal plasticity as a mediator of neuroendocrine and behavioral responses to steroids. Neuroscience 138, 977-85.

[2] Kerr, J.E., Allore, R.J., Beck, S.G. and Handa, R.J. (1995) Distribution and hormonal regulation of androgen receptor (AR) and AR messenger ribonucleic acid in the rat hippocampus. Endocrinology 136, 3213-21.

[3] Janowsky, J.S. (2006) The role of androgens in cognition and brain aging in men. Neuroscience 138, 1015-20.

[4] Vasudevan, N. and Pfaff, D.W. (2008) Non-genomic actions of estrogens and their interaction with genomic actions in the brain. Front Neuroendocrinol 29, 238-57.

[5] Gibbs, T.T., Russek, S.J. and Farb, D.H. (2006) Sulfated steroids as endogenous neuromodulators. Pharmacol Biochem Behav 84, 555-67.

[6] Johansson, T., Frandberg, P.A., Nyberg, F. and Le Greves, P. (2008) Molecular mechanisms for nanomolar concentrations of neurosteroids at NR1/NR2B receptors. J Pharmacol Exp Ther 324, 759-68.

[7] Sarkey, S., Azcoitia, I., Garcia-Segura, L.M., Garcia-Ovejero, D. and DonCarlos, L.L. (2008) Classical androgen receptors in non-classical sites in the brain. Horm Behav 53, 753-64.

[8] Toran-Allerand, C.D. (2004) Estrogen and the brain: beyond ER-alpha and ERbeta. Exp Gerontol 39, 1579-86.

[9] Gatson, J.W., Kaur, P. and Singh, M. (2006) Dihydrotestosterone differentially modulates the mitogen-activated protein kinase and the phosphoinositide 3kinase/Akt pathways through the nuclear and novel membrane androgen receptor in C6 cells. Endocrinology 147, 2028-34.

[10] Nguyen, T.V., Yao, M. and Pike, C.J. (2005) Androgens activate mitogenactivated protein kinase signaling: role in neuroprotection. J Neurochem 94, 163951 .

[11] Talih, F., Fattal, O. and Malone, D., Jr. (2007) Anabolic steroid abuse: psychiatric and physical costs. Cleve Clin J Med 74, 341-4, 346, 349-52.

[12] Midgley, S.J., Heather, N. and Davies, J.B. (2001) Levels of aggression among a group of anabolic-androgenic steroid users. Med Sci Law 41, 309-14.

[13] Cunningham, R.L. and McGinnis, M.Y. (2006) Physical provocation of pubertal anabolic androgenic steroid exposed male rats elicits aggression towards females. Horm Behav 50, 410-6.

[14] Bing, O., Heilig, M., Kakoulidis, P., Sundblad, C., Wiklund, L. and Eriksson, E. (1998) High doses of testosterone increase anticonflict behaviour in rat. Eur Neuropsychopharmacol 8, 321-3.

[15] Bitran, D., Kellogg, C.K. and Hilvers, R.J. (1993) Treatment with an anabolicandrogenic steroid affects anxiety-related behavior and alters the sensitivity of cortical GABAA receptors in the rat. Horm Behav 27, 568-83. 
[16] Aikey, J.L., Nyby, J.G., Anmuth, D.M. and James, P.J. (2002) Testosterone rapidly reduces anxiety in male house mice (Mus musculus). Horm Behav 42, 448-60.

[17] Chen, X., Garelick, M.G., Wang, H., Lil, V., Athos, J. and Storm, D.R. (2005) PI3 kinase signaling is required for retrieval and extinction of contextual memory. Nat Neurosci 8, 925-31.

[18] Isosaka, T., Hattori, K., Kida, S., Kohno, T., Nakazawa, T., Yamamoto, T., Yagi, T. and Yuasa, S. (2008) Activation of Fyn tyrosine kinase in the mouse dorsal hippocampus is essential for contextual fear conditioning. Eur J Neurosci 28, 97381.

[19] Rossbach, U.L., Steensland, P., Nyberg, F. and Le Greves, P. (2007) Nandroloneinduced hippocampal phosphorylation of NMDA receptor subunits and ERKs. Biochem Biophys Res Commun 357, 1028-33.

[20] Kelleher, R.J., 3rd, Govindarajan, A., Jung, H.Y., Kang, H. and Tonegawa, S. (2004) Translational control by MAPK signaling in long-term synaptic plasticity and memory. Cell 116, 467-79.

[21] Nateri, A.S., Raivich, G., Gebhardt, C., Da Costa, C., Naumann, H., Vreugdenhil, M., Makwana, M., Brandner, S., Adams, R.H., Jefferys, J.G., Kann, O. and Behrens, A. (2007) ERK activation causes epilepsy by stimulating NMDA receptor activity. Embo J 26, 4891-901.

[22] Takasu, M.A., Dalva, M.B., Zigmond, R.E. and Greenberg, M.E. (2002) Modulation of NMDA receptor-dependent calcium influx and gene expression through EphB receptors. Science 295, 491-5.

[23] Hollingsworth, E.B., McNeal, E.T., Burton, J.L., Williams, R.J., Daly, J.W. and Creveling, C.R. (1985) Biochemical characterization of a filtered synaptoneurosome preparation from guinea pig cerebral cortex: cyclic adenosine $3^{\prime}: 5^{\prime}$-monophosphate-generating systems, receptors, and enzymes. J Neurosci 5, 2240-53.

[24] Vandesompele, J., De Preter, K., Pattyn, F., Poppe, B., Van Roy, N., De Paepe, A. and Speleman, F. (2002) Accurate normalization of real-time quantitative RTPCR data by geometric averaging of multiple internal control genes. Genome Biol 3, RESEARCH0034.

[25] Kelleher, R.J., 3rd, Govindarajan, A. and Tonegawa, S. (2004) Translational regulatory mechanisms in persistent forms of synaptic plasticity. Neuron 44, 5973.

[26] Tang, S.J., Reis, G., Kang, H., Gingras, A.C., Sonenberg, N. and Schuman, E.M. (2002) A rapamycin-sensitive signaling pathway contributes to long-term synaptic plasticity in the hippocampus. Proc Natl Acad Sci U S A 99, 467-72.

[27] Grunwald, I.C., Korte, M., Adelmann, G., Plueck, A., Kullander, K., Adams, R.H., Frotscher, M., Bonhoeffer, T. and Klein, R. (2004) Hippocampal plasticity requires postsynaptic ephrinBs. Nat Neurosci 7, 33-40.

[28] Migani, P., Bartlett, C., Dunlop, S., Beazley, L. and Rodger, J. (2007) Ephrin-B2 immunoreactivity distribution in adult mouse brain. Brain Res 1182, 60-72.

[29] Lee, Y.F., Lin, W.J., Huang, J., Messing, E.M., Chan, F.L., Wilding, G. and Chang, C. (2002) Activation of mitogen-activated protein kinase pathway by the 
antiandrogen hydroxyflutamide in androgen receptor-negative prostate cancer cells. Cancer Res 62, 6039-44.

[30] Peterziel, H., Mink, S., Schonert, A., Becker, M., Klocker, H. and Cato, A.C. (1999) Rapid signalling by androgen receptor in prostate cancer cells. Oncogene $18,6322-9$.

[31] Zhu, X., Li, H., Liu, J.P. and Funder, J.W. (1999) Androgen stimulates mitogenactivated protein kinase in human breast cancer cells. Mol Cell Endocrinol 152, 199-206.

[32] Tabori, N.E., Stewart, L.S., Znamensky, V., Romeo, R.D., Alves, S.E., McEwen, B.S. and Milner, T.A. (2005) Ultrastructural evidence that androgen receptors are located at extranuclear sites in the rat hippocampal formation. Neuroscience 130, 151-63.

[33] MacLusky, N.J., Hajszan, T., Johansen, J.A., Jordan, C.L. and Leranth, C. (2006) Androgen effects on hippocampal CA1 spine synapse numbers are retained in $\mathrm{Tfm}$ male rats with defective androgen receptors. Endocrinology 147, 2392-8.

[34] Gong, R. and Tang, S.J. (2006) Mitogen-activated protein kinase signaling is essential for activity-dependent dendritic protein synthesis. Neuroreport 17, 15758.

[35] Li, B., Chen, N., Luo, T., Otsu, Y., Murphy, T.H. and Raymond, L.A. (2002) Differential regulation of synaptic and extra-synaptic NMDA receptors. Nat Neurosci 5, 833-4.

[36] Prybylowski, K., Chang, K., Sans, N., Kan, L., Vicini, S. and Wenthold, R.J. (2005) The synaptic localization of NR2B-containing NMDA receptors is controlled by interactions with PDZ proteins and AP-2. Neuron 47, 845-57.

[37] Bramham, C.R. and Wells, D.G. (2007) Dendritic mRNA: transport, translation and function. Nat Rev Neurosci 8, 776-89.

[38] Lee, H.K. (2006) Synaptic plasticity and phosphorylation. Pharmacol Ther 112, 810-32.

[39] Banko, J.L., Hou, L. and Klann, E. (2004) NMDA receptor activation results in PKA- and ERK-dependent Mnk1 activation and increased eIF4E phosphorylation in hippocampal area CA1. J Neurochem 91, 462-70.

[40] Hajszan, T., MacLusky, N.J. and Leranth, C. (2008) Role of androgens and the androgen receptor in remodeling of spine synapses in limbic brain areas. Horm Behav 53, 638-46.

[41] Minkin, D.M., Meyer, M.E. and van Haaren, F. (1993) Behavioral effects of longterm administration of an anabolic steroid in intact and castrated male Wistar rats. Pharmacol Biochem Behav 44, 959-63.

[42] Rocha, V.M., Calil, C.M., Ferreira, R., Moura, M.J. and Marcondes, F.K. (2007) Influence of anabolic steroid on anxiety levels in sedentary male rats. Stress 10, 326-31.

[43] Edinger, K.L. and Frye, C.A. (2007) Sexual experience of male rats influences anxiety-like behavior and androgen levels. Physiol Behav 92, 443-53.

[44] Hermans, E.J., Putman, P., Baas, J.M., Koppeschaar, H.P. and van Honk, J. (2006) A single administration of testosterone reduces fear-potentiated startle in humans. Biol Psychiatry 59, 872-4. 
[45] Thiblin, I., Kristiansson, M. and Rajs, J. (1997) Anabolic androgenic steroids and behavioural patterns among violent offenders. Journal of Forensic Psychiatry \& Psychology 8, 299 - 310.

[46] Edinger, K.L. and Frye, C.A. (2006) Intrahippocampal administration of an androgen receptor antagonist, flutamide, can increase anxiety-like behavior in intact and DHT-replaced male rats. Horm Behav 50, 216-22.

[47] Almeida, O.P. and Barclay, L. (2001) Sex hormones and their impact on dementia and depression: a clinical perspective. Expert Opin Pharmacother 2, 527-35.

[48] Compagnone, N.A. and Mellon, S.H. (2000) Neurosteroids: biosynthesis and function of these novel neuromodulators. Front Neuroendocrinol 21, 1-56.

[49] Lambert, J.J., Belelli, D., Peden, D.R., Vardy, A.W. and Peters, J.A. (2003) Neurosteroid modulation of GABAA receptors. Prog Neurobiol 71, 67-80.

[50] Johansson, T. and Le Greves, P. (2005) The effect of dehydroepiandrosterone sulfate and allopregnanolone sulfate on the binding of [(3)H]ifenprodil to the $\mathrm{N}$ methyl-d-aspartate receptor in rat frontal cortex membrane. J Steroid Biochem Mol Biol 94, 263-6.

[51] Chen, L., Miyamoto, Y., Furuya, K., Mori, N. and Sokabe, M. (2007) PREGS induces LTP in the hippocampal dentate gyrus of adult rats via the tyrosine phosphorylation of NR2B coupled to ERK/CREB [corrected] signaling. J Neurophysiol 98, 1538-48. 


\section{Acknowledgements}

LNCaP cells were a kind gift of Dr. Maria Norlin, Dept of Pharmaceutical Biosciences, Uppsala University. This study was supported by Swedish Brain Foundation, Tore Nilsson Foundation and Stohnes Foundation (M. L.). Swedish Research Council (Grant 9459) (F. N.). Gunvor och Josef Anérs Foundation and Åhléns Foundation (P. L.) 


\section{Figure legends:}

Fig. 1

Protein profile of the hippocampal synaptoneurosome preparation. Immunoblots of different fractions (crude homogenate, synaptoneurosomes and supernatant) were compared for their content of GluN2A (A), GluN2B (B), ERK1 (C), ERK2 (D), ephrinB2 (E) and eIF4E (F). Representative immunoblots for each fraction are shown on top of each diagram. The values are means \pm SEM of two independent Western blot analyses.

Fig. 2

The effect of subchronic $(5 \mathrm{~d})$ flutamide and/or acute $(2 \mathrm{~h})$ 19NT treatment on the $\mathrm{p}$ ERK1 (A), p-ERK2 (B), p-GluN2B ${ }^{\mathrm{Y} 1472}(\mathbf{C})$ and GluN2B (D) in rat hippocampal synaptoneurosomes. Representative immunoblots for each group of rats are shown on top of each diagram. Data is expressed as mean \pm SEM of two independently conducted Western blot analyses. ${ }^{*} P=0.06,{ }^{*} P<0.05,{ }^{* *} P<0.01,{ }^{* * *} P<0.001$ (one-way ANOVA followed by Fisher's PLSD post hoc test).

\section{Fig.3}

The influence of time on the effects of 19NT on synaptoneurosomal p-ERK1 (A), pERK2 (B), p-GluN2B ${ }^{\mathrm{Y} 1472}(\mathbf{C})$ and GluN2B (D) in male rat hippocampus. Representative immunoblots for each group of rats are shown on top of each diagram. The values are means \pm SEM of two independently conducted Western blot analyses. $* P<0.05$, ${ }^{* *} P<$ 0.01 (one-way ANOVA followed by Fisher's PLSD post hoc test).

Fig.4

Diagrams show the effect of subchronic ( $5 \mathrm{~d}$ ) flutamide and/or acute $(2 \mathrm{~h}$ or $6 \mathrm{~h}) 19 \mathrm{NT}$ treatment on GluN2A (A), p-GluN2A ${ }^{\mathrm{S} 1232}(\mathbf{B})$, ephrinB2 $(\mathbf{C})$ and p-eIF4E (D) in rat hippocampal synaptoneurosomes. Representative immunoblots for each group of rats are shown on top of each diagram. The values are means \pm SEM of two independently conducted Western blot analyses. One-way-ANOVA analysis did not show any significant variation between the different treatments.

\section{Fig.5}

Immunoprecipitation and detection of androgen receptor (AR). This analysis shows the presence of AR protein $(\sim 110 \mathrm{kD})$ in hippocampal synaptoneurosomes (SNS) of the male rat. AR is known to be expressed in the total protein extract of human prostate carcinoma cell line (LNCaP) which served as the positive control.

Tab. 1 mRNA expression of NMDA receptor subunits GluN2A and GluN2B in rat hippocampal tissue. The data are presented as mean \pm SEM. One-way-ANOVA analysis did not reveal any significant variation between the different treatments. 

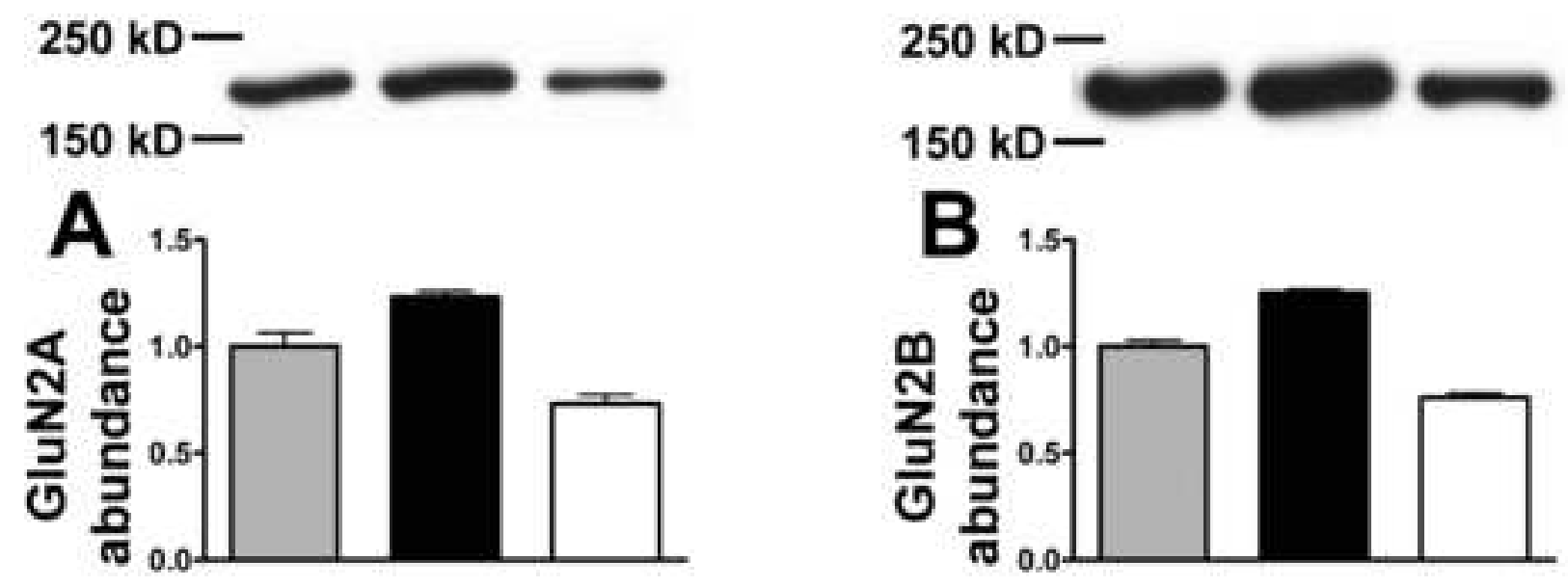

50 kD -

$50 \mathrm{kD}-$

$37 \mathrm{kD}-$

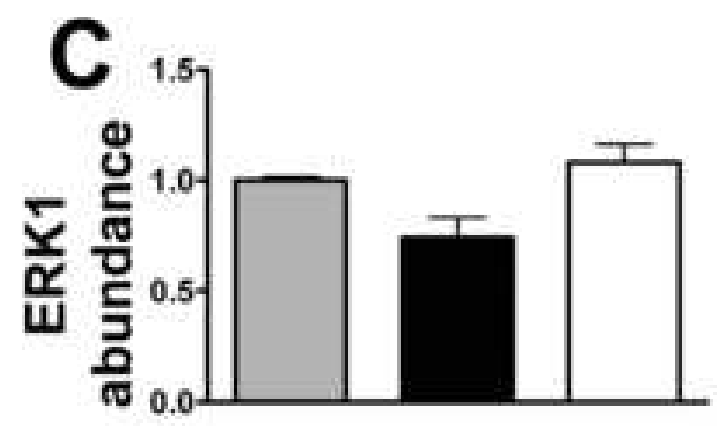

$50 \mathrm{kD}-$

$37 \mathrm{kD}-$

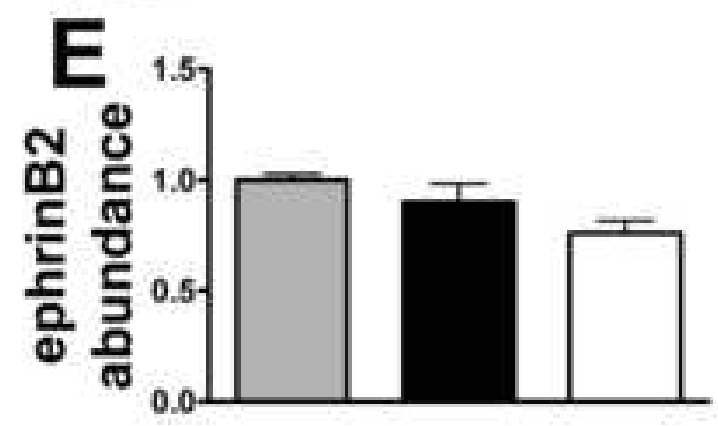

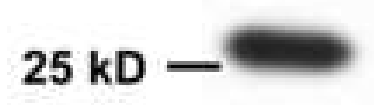

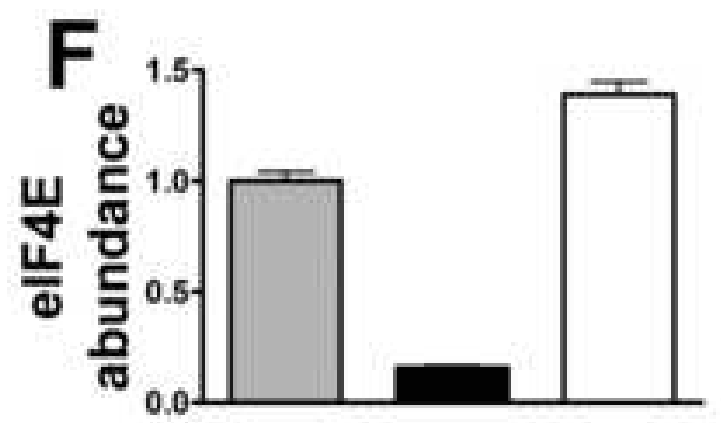


A

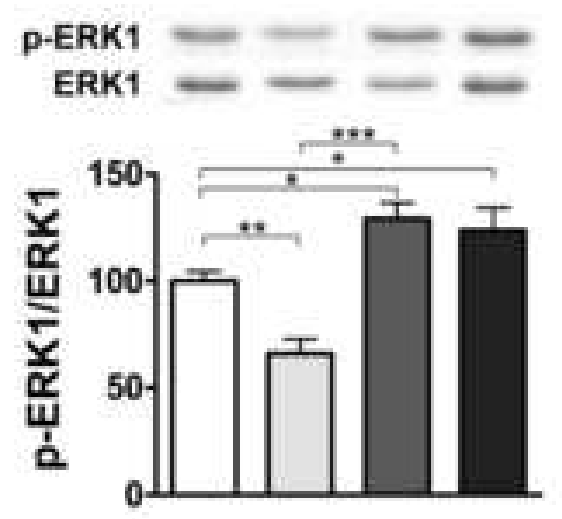

B

p-ERK2

ERK2

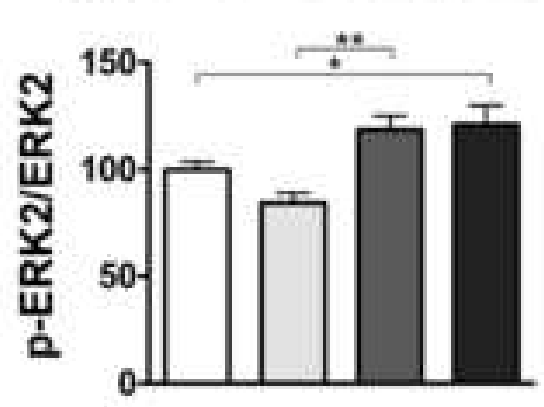

C

p-GluN2B

GluN2B

$\square$ oil+oil $2 \mathrm{~h} \quad \square$ oil+19NT $2 \mathrm{~h}$

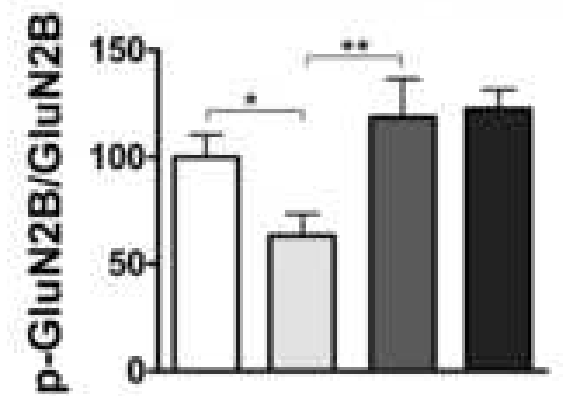

Flu+19NT $2 \mathrm{~h}$
D

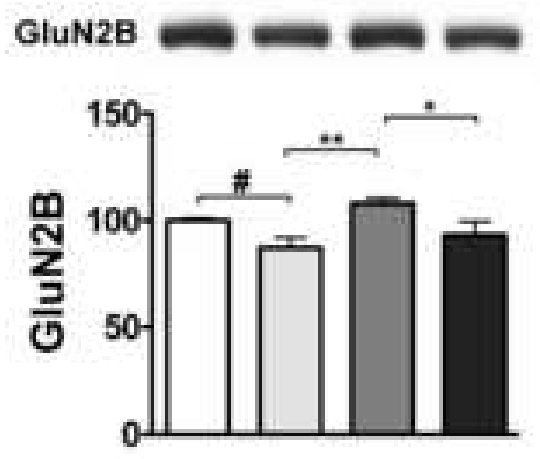

Flu+oil $2 \mathrm{~h}$ 
A
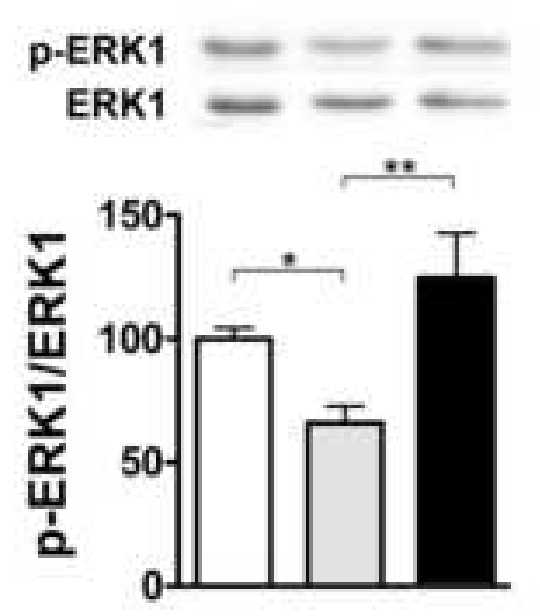

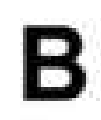

P-ERK2 ERK2

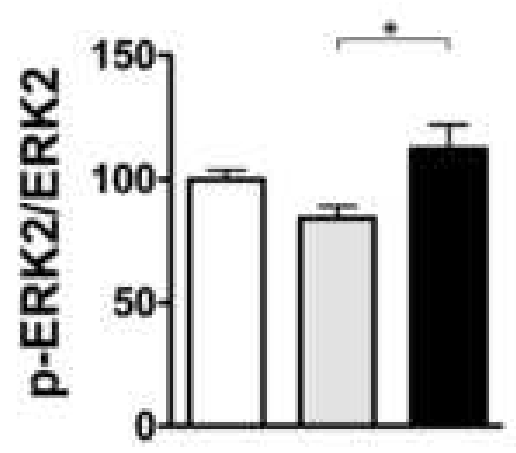

C

p-GluN2B

GluN2B

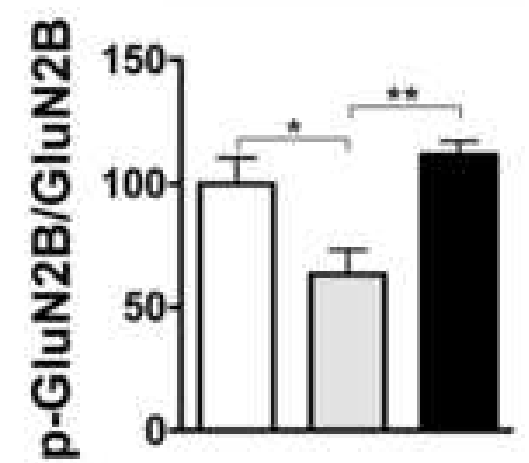

D

GluN2B

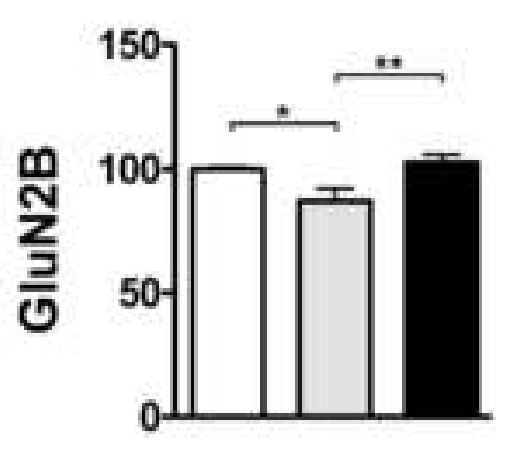

$\square$ oil+oil 2 h $\square$ oil+19NT 2 h $\square$ oil+19NT 6 h 
GluN2A

A

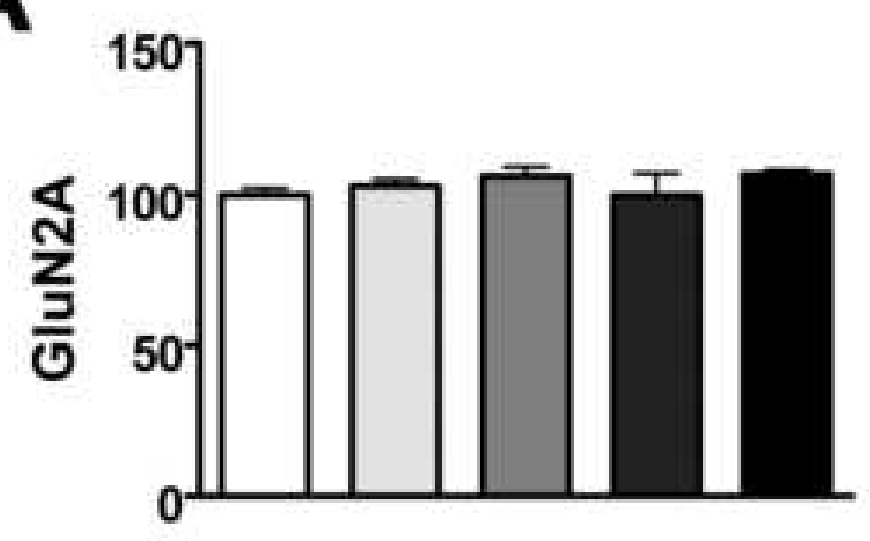

ephrinB2

C

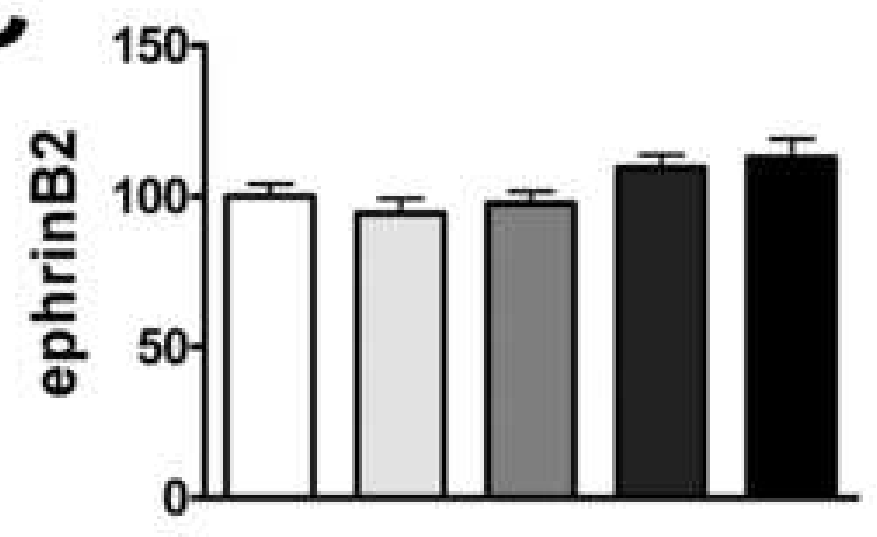

p-GluN2A GluN2A

B

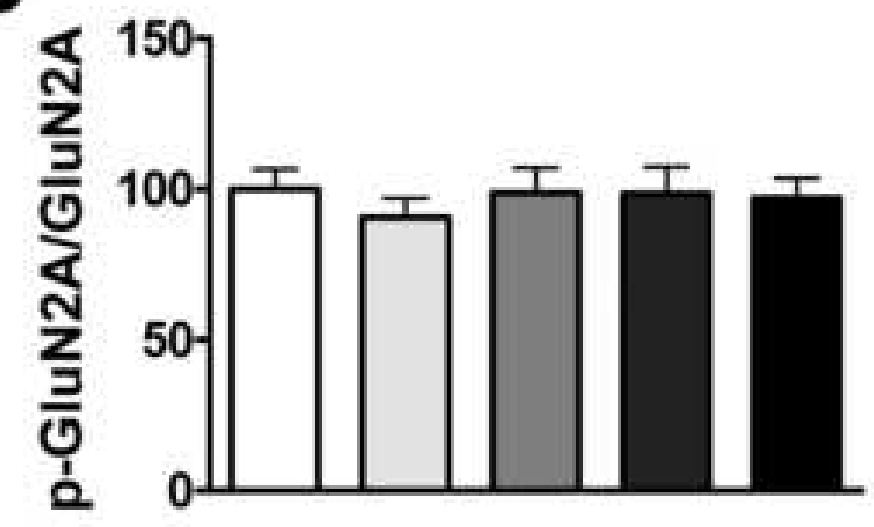

p-elF4E elF4E

D

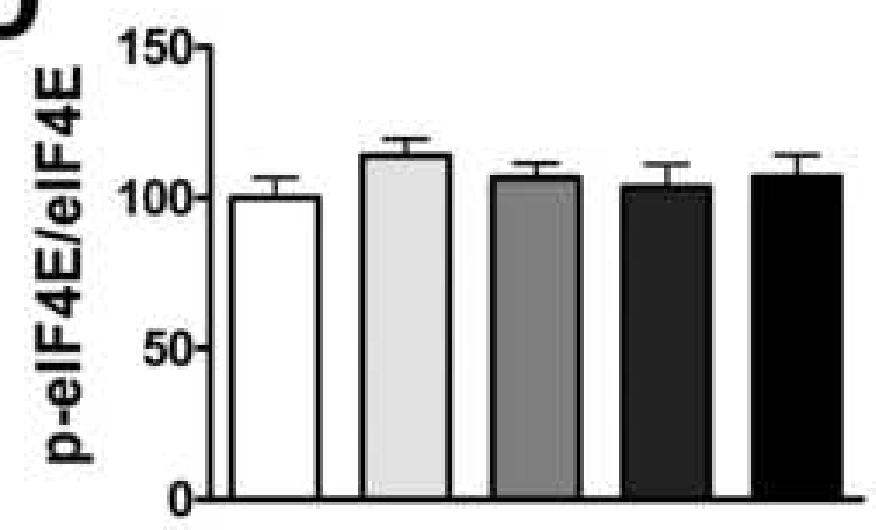

$\square$ oil+oil 2 h $\square$ oil+19NT 2 h $\square$ Flu+19NT 2 h $\square$ Flu+oil 2 h $\square$ oil+19NT 6 h 
$250 \mathrm{kD}-$

150 kD -

100 kD -

$$
75 \text { kD - }
$$


Table 1 - mRNA expression levels of the NMDA receptor subunit GluN2A and GluN2B in rat hippocampus

\begin{tabular}{|c|ccccc|}
\cline { 2 - 6 } \multicolumn{1}{c|}{ gene } & oil+oil 2 $\mathrm{h}$ & oil+19NT 2 $\mathrm{h}$ & FLU+19NT 2 $\mathrm{h}$ & FLU+oil 2 $\mathrm{h}$ & oil+19NT 6 h \\
\hline GluN2A & $100.0 \pm 6.7$ & $101.0 \pm 4.7$ & $100.2 \pm 6.3$ & $103.7 \pm 7.0$ & $91.3 \pm 4.4$ \\
GluN2B & $100.0 \pm 3.1$ & $103.9 \pm 7.5$ & $102.9 \pm 3.5$ & $112.8 \pm 4.2$ & $104.0 \pm 4.2$ \\
\hline
\end{tabular}

